Article

\title{
Study on Water Absorption-Dehydration Characteristics for SAP Composite Soil for Rainwater Harvesting
}

\author{
Youwei Qin ${ }^{1}$, Tao Yang ${ }^{1, *}$, Siyuan Wang ${ }^{2}$, Fangling Hou ${ }^{3}$, Pengfei Shi ${ }^{1}$ and Zhenya Li $^{1}$ \\ 1 State Key Laboratory of Hydrology-Water Resources and Hydraulic Engineering, Centre for Global Change \\ and Water Cycle, Hohai University, Nanjing 210098, China; youwei.qin@hhu.edu.cn (Y.Q.); \\ pfshi@hhu.edu.cn (P.S.); 20190924@hhu.edu.cn (Z.L.) \\ 2 Shenzhen Water Planning and Design Institute, Shenzhen 518001, China; wangsy01@swpdi.com \\ 3 Nanjing Hydraulic Research Institute, Nanjing 210029, China; flhou@nhri.cn \\ * Correspondence: tao.yang@hhu.edu.cn
}

Received: 4 June 2020; Accepted: 21 August 2020; Published: 25 August 2020

\begin{abstract}
As a water absorption material, superabsorbent polymer (SAP) has gained its popularity in agriculture and environmental remediations. This study conducted a comparative investigation on saturated water content of cinnamon soil mixed with SAP. Two SAPs, SAP1 and SAP2, with different behaviors were tested, where SAP1 is an organic superabsorbent polymer, and SAP2 is polyacrylic acid sodium salt polymer. The saturated water content of SAP composite cinnamon soil was investigated with the weighing method. The repeated water absorption capacity and dehydration behavior of SAP composite soil under different designed rainfall intensity were investigated with a soil column tester. The results showed that (1) cinnamon soil mixed with SAP increased the saturated soil water content, and SAP1 was more effective than SAP2; (2) SAP held strong water absorption ability and recycling efficiency with eight repeated absorption-dehydration tests; (3) the average dehydration time for SAP composite soil were $626 \mathrm{~h}$ and $1214 \mathrm{~h}$ under 5-year and 10-year design rainfall intensities.
\end{abstract}

Keywords: superabsorbent polymer; composite soil; soil column test; repeated water absorption; average dehydration time

\section{Introduction}

With the rapid development of urban construction, urban waterlogging has become a major problem in modern cities. The low impact development approach [1-3] and green infrastructure practices $[4,5]$ have been widely used in urban construction to mitigate the negative effects of urbanization. To resolve urban waterlogging, the Chinese government initiated the sponge city plan in 2015 with 30 pilot sponge cities [6,7]. A number of studies have been conducted to investigate the effect of sponge cities in urban flood control, rainwater harvest, water quality improvement, and ecological restoration [8-13]. This research introduced the usage of superabsorbent polymers (SAP) into sunken greenbelt structure construction in Jinan, which is one of the 30 pilot sponge cities.

SAP is a kind of macromolecule polymer with super-high water absorption and retention capacity. It can absorb water with a mass more than a hundred times of its own weight in a very short period [14]. SAP has been widely used in agriculture, water retention, and environmental remediations [15-21]. Yang et al. [22] studied water retention characteristics of SAP composite soil with mixing ratios of $0.15 \%$, $0.3 \%$, and $0.45 \%$ and concluded that SAP can sufficiently improve the water retention behavior of sandy loam soil. Suresh et al. [23] studied the effect of SAP on water use efficiency for container-grown cherry tomatoes and concluded that water use efficiency was significantly higher with SAP mixing ratio of $0.5 \%$. Li et al. [24] studied the water absorption behavior of SAP mixed with sulfoaluminate 
cementitious materials and concluded that the water absorption rate increased by $38.3 \%$. Watanabe et al. [25] investigated the effect of the SAP mixing ration on sandy soil water content and concluded that $0.15 \%$ polymer was the optimal mixing ratio. Khodadadi Dehkordi [26] studied the water holding capacity and saturated water content of three SAP composite soils with mixing ratios of $0.2 \%, 0.4 \%$, and $0.6 \%$ and concluded that the maximal water content increment occurred with SAP content of $0.6 \%$. Besides the saturated water content, a number of researches studied the dehydration behavior of SAP composite soil. Watanabe et al. [25] investigated the water contents of two polymers and showed that the amount of soil water content gradually decreased throughout the 15 days of the experiment period, and polymer P was higher than polymer S. Khodadadi Dehkordi [26] showed that the soil water content of composite soil was completely dried between 10 and 13 days, while the soil without SAP completely dried after 4 days. There were also a limited number of researches on the repeated water absorption behavior of SAP. Mudiyanselage and Neckers [27] studied the reversible water absorption behavior of SAPs and reported that average water absorbency decreased dramatically after the first test, then almost did not change afterward. More recent research by Bai et al. [28] investigated the repeated usage of four SAPs and showed that water absorbency decreased as the SAP's concentration reduced with repeated utilization.

Although there are a number of studies on SAP, their application is mostly with sandy soil, its application in composite soil structure has not been fully explored. This study conducts an intensive study of SAPs on cinnamon soil, as well as its application in composite soil structure. The repeated absorption behavior and the dehydration behavior of SAP have been investigated with a composite soil structure.

\section{Aims}

In this study, a comparative soil column test was carried out to investigate the effect of SAP on cinnamon soil. The repeated absorption behavior of the composite soil layer with SAP was explored to evaluate the reusable capability of SAP. In addition, the dehydration behavior of SAP composite soil was investigated. These results can provide a theoretical basis for the construction of a sunken greenbelt, which has important theoretical significance and practical value for sponge city construction. The aims of this paper are as follows:

1. Investigate the saturated water content of SAP mixed cinnamon soil with mixing ratio ranges between $0.1 \%$ and $1 \%$;

2. Demonstrate the performance of repeated water absorption behavior of SAPs with soil column tests;

3. Test the average dehydration time for SAP composite soil with soil column tests.

The remainder of this paper is organized as follows: Section 3 describes the test scheme, including soil characteristic, SAPs, and test setups. Section 4 presents the study results, followed by the discusses and interprets of findings. Section 5 summarizes the main conclusions.

\section{Test Scheme}

\subsection{Material}

\subsubsection{Soil}

The experiment was conducted for the construction of a sunken greenbelt structure in Jinan, Shandong Province. Cinnamon soil accounts for $74.1 \%$ of the total soil in Jinan and was selected as raw soil for all the tests. Cinnamon soil has the following soil properties: clay content $(<2 \mu \mathrm{m})=37 \%$, silt content $(2-50 \mu \mathrm{m})=59 \%$, sand content $(50-2000 \mu \mathrm{m})=4 \%$, $\mathrm{pH}$ value ranges from 7 to 7.5 , soil organic matter $10.8 \mathrm{~g} / \mathrm{kg}$, dry bulk density around $1.3 \mathrm{~g} / \mathrm{cm}^{3}$. 


\subsubsection{SAP}

Two kinds of SAPs materials were selected in this study as follows:

(1) Organic superabsorbent polymer produced by the Henan Jinyu chemical company, named SAP1 in the experiment, which is widely used in agriculture.

(2) Low density cross-linked polyacrylic acid sodium salt polymer produced by the Shandong Yusuo company, named SAP2 in the experiment, which is reported to have a high absorbent capacity.

\subsection{Test Setup}

\subsubsection{Saturated Soil Water Content}

The saturated soil water content of SAP mixed cinnamon soil was measured with the weighing method. Cinnamon soil was first dried and sifted by a soil sieve with a diameter of $1 \mathrm{~mm}$. The sifted cinnamon soil was then divided into groups for testing, with $200 \mathrm{~g}$ in each group. The saturated soil water content of the SAP mixed cinnamon soil was measured with mixing ratios of $0.1 \%, 0.25 \%$, $0.5 \%, 0.75 \%$, and $1 \%$. When measuring saturated soil water content, SAP was first mixed evenly with sifted cinnamon soil, and then put into a soil cutter and soaked for $24 \mathrm{~h}$ to absorb water sufficiently. The saturated water content of the composite soil was then measured by the weighing method. Soil water content was measured five times, and the average value was taken. The soil water content by weight was calculated with the following equation:

$$
f(\%)=\frac{\left(W_{1}-W_{2}-200\right) \times 100}{200}
$$

where $f(\%)$ is saturated water content, $W_{1}$ is the total weight of saturated soil and soil cutter $(\mathrm{g}), W_{2}$ is the total weight of soil cylinder $(\mathrm{g})$.

\subsubsection{Soil Column Test}

A soil column tester was constructed to mimic the behavior of an actual sunken greenbelt structure. The schematic diagram of a sunken greenbelt structure is shown in Figure 1a. The bottom layer is a raw cinnamon soil layer, above which is a $15 \mathrm{~cm}$ gravel layer evenly mixed with gravel diameter sizes of $16-32 \mathrm{~mm}$ and 8-16 mm. A mixed layer of quartz sand and activated carbon is laid on top of the gravel layer with a thickness of $20 \mathrm{~cm}$, and the mixing ratio between quartz sand and activated carbon is 5:1. A composite soil layer, mixed by cinnamon soil and SAP with a ratio 1:1000, is laid above with a thickness of $10 \mathrm{~cm}$. On top of the composite soil layer is a $15 \mathrm{~cm}$ vermiculite-soil layer mixed by vermiculite and cinnamon soil with a ratio of 5:1000. The Manila grass layer is laid on top of soil column tester to prevent possible erosion of surface soil. During the soil column test, the soil column tester can be reassembled to meet the demands of the test. A standard soil column tester is shown in Figure $1 \mathrm{~b}$, which was constructed with five layers, where the Manila grass layer was not used in soil column tester. The soil column tester was conducted in a cylinder with a diameter of $35 \mathrm{~cm}$. 
(a)

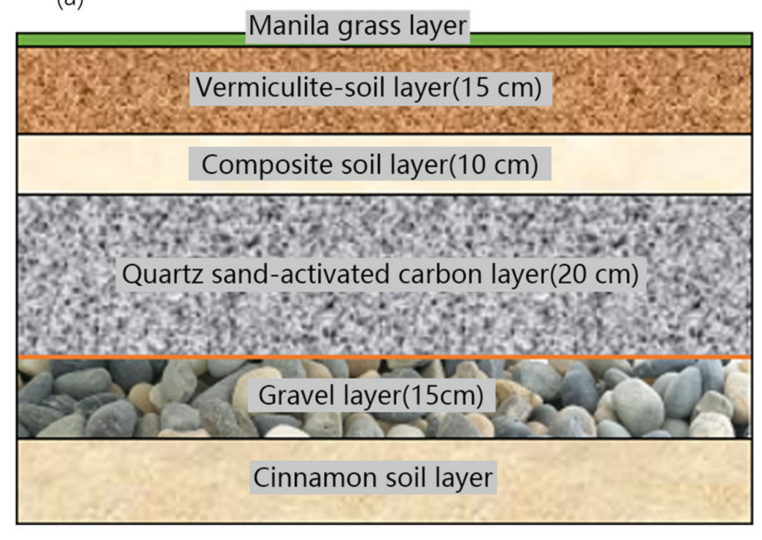

(b)

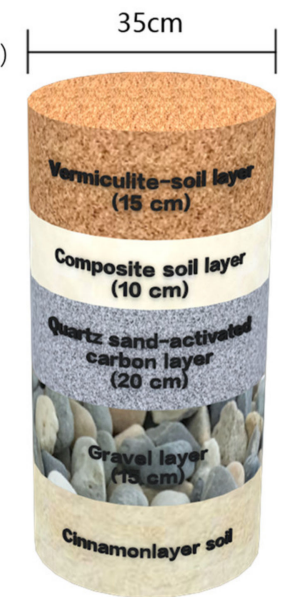

Figure 1. Schematic diagram of sunken greenbelt structure (a), and a standard soil column tester (b).

Repeated absorption tests for SAP were conducted using a simplified soil column tester with two layers, an SAP composite soil layer and a gravel layer. The cinnamon soil with dry bulk density around $1.3 \mathrm{~g} / \mathrm{cm}^{3}$ was mixed with SAP1 in the composite soil layer. The SAP1, with a mixing ratio of $0.1 \%$, was used in the repeated absorption experiment. Three design rainfall intensity scenarios were used in the repeated absorption test: Group A with design rainfall of $1.01 \mathrm{~mm} / \mathrm{min}$ (5-year design rainfall intensity), Group B with rainfall of $1.16 \mathrm{~mm} / \mathrm{min}$ (10-year design rainfall intensity), and Group C with alteration of a 15-year design rainfall intensity of $1.25 \mathrm{~mm} / \mathrm{min}$ and 5-year design rainfall intensity of $1.01 \mathrm{~mm} / \mathrm{min}$. The experiment was repeated 8 times, and in each replication, a wetting and drying cycle was conducted. In each experiment, SAP composite soil samples were dried in an oven at $50{ }^{\circ} \mathrm{C}$ for about $10 \mathrm{~h}$, and the soil water content was measured every $2 \mathrm{~h}$ to control the initial soil water content of each replicate. The soil water content was measured by weight using Equation (1). Table 1 listed the initial soil water contents of 8 replications for three groups, which were roughly the same ranged from $11 \%$ to $16 \%$.

Table 1. Initial soil water content of three groups (\%).

\begin{tabular}{cccccccccc}
\hline & $\mathbf{1}$ & $\mathbf{2}$ & $\mathbf{3}$ & $\mathbf{4}$ & $\mathbf{5}$ & $\mathbf{6}$ & $\mathbf{7}$ & $\mathbf{8}$ & Average \\
\hline Group A & 15.50 & 14.30 & 11.90 & 14.20 & 15.50 & 12.00 & 13.70 & 11.70 & 13.60 \\
Group B & 15.70 & 15.60 & 13.20 & 16.30 & 11.20 & 14.50 & 15.70 & 11.80 & 14.25 \\
Group C & 12.30 & 12.70 & 15.10 & 11.50 & 12.80 & 11.00 & 11.10 & 13.80 & 12.54 \\
\hline
\end{tabular}

In each replication, a constant inflow was generated to mimic the design rainfall intensity. An artificial rainfall simulator was not used in this experiment as the diameter of the soil column tester was too small, which could introduce significant bias. The constant inflow was stopped at $60 \mathrm{~min}$, and the cumulated outflow, released at the bottom of soil column tester, and the cumulated overflow above SAP composite soil layer was recorded every $3 \mathrm{~min}$. As the gravel layer does not have water absorption behavior, the cumulated water absorption of SAP was calculated as follow:

$$
W A=\text { inFlow }- \text { outFlow - overFlow }
$$

where WA is the cumulated water absorption of SAP composite soil (mm), inFlow is the cumulated inflow (mm), outFlow is the cumulated outflow at the bottom of soil column tester (mm), overFlow is the cumulated water above SAP composite soil layer ( $\mathrm{mm}$ )

The dehydration test was conducted with a standard soil column tester with diameter $35 \mathrm{~cm}$ as illustrated in Figure 1b, including a gravel layer with a thickness of $15 \mathrm{~cm}$, a quartz sand-activated carbon layer with a thickness of $20 \mathrm{~cm}$, a SAP composite layer with a thickness of $10 \mathrm{~cm}$, and a vermiculite-soil 
layer with a thickness of $15 \mathrm{~cm}$. SAP1 with a mixing ratio of $0.1 \%$ was used in the SAP composite soil layer. The experiment was conducted under 5-year and 10-year design rainfall intensity. Group D used constant inflow with a design rainfall intensity of $1.16 \mathrm{~mm} / \mathrm{min}$ (10-year design rainfall intensity), and Group E used a constant inflow with a design rainfall intensity of $1.01 \mathrm{~mm} / \mathrm{min}$ (5-year design rainfall intensity). In each experiment, a constant inflow was generated to mimic the design rainfall intensity. The HOBO S-SMD-M005 soil moisture smart sensor (https://www.onsetcomp.com) was used to automatically measure the volumetric soil water content in the vermiculite soil layer, composite soil layer, and activated carbon quartz sand layer. The constant inflow was stopped at $60 \mathrm{~min}$, and the water content in the three layers was recorded every $1 \mathrm{~h}$ for 14 days. To mimic the average dehydration time of the three layers under natural conditions, the test was conducted in outdoor conditions with temperature variations from $-2{ }^{\circ} \mathrm{C}$ to $16^{\circ} \mathrm{C}$, and humidity between $62 \%$ and $95.6 \%$.

\section{Results and Discussion}

\subsection{Saturated Soil Water Content}

Saturated soil water content represents the water storage capacity of soil, which represents a key physical property of soil. In this experiment, the saturated soil water content of SAP composite cinnamon soil was measured, and the increment of soil water content was evaluated. Two SAPs, SAP1 and SAP2, were used in the composite cinnamon soil, with mixing ratios of $0.1 \%, 0.25 \%, 0.5 \%, 0.75 \%$, and $1 \%$. The results were compared against a controlled group with raw cinnamon soil. The results are shown in Figure 2.
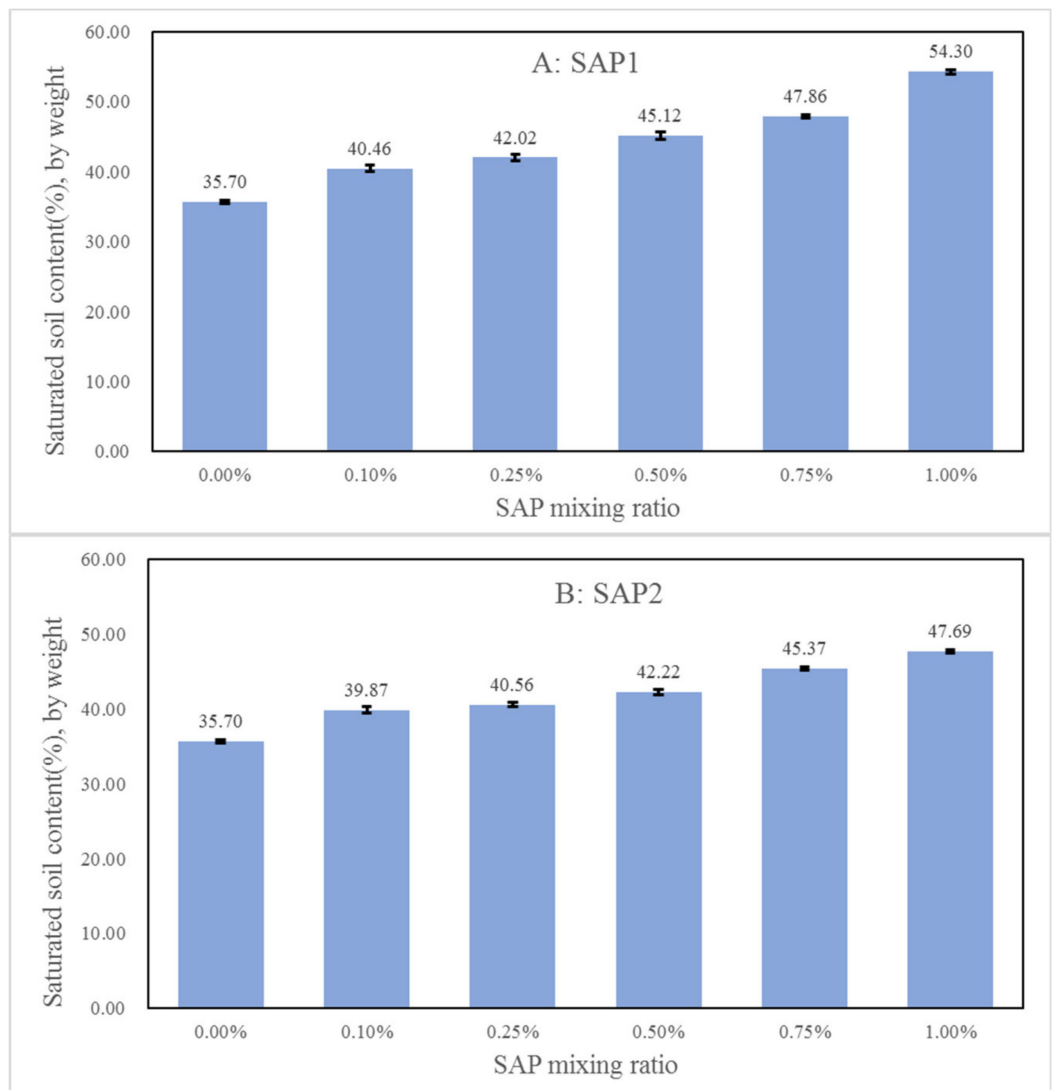

Figure 2. Saturated soil water content of superabsorbent polymer (SAP) composite cinnamon soil with different SAP mixing ratios. The controlled group with raw cinnamon soil was the one with a mixing ratio of $0.00 \%$. Panel (A) shows the saturated soil water content of SAP1, and Panel (B) shows the saturated soil water content of SAP2. The error bars are the standard deviation of soil water content with five times measurement data. 
As was shown in Figure 2, SAP1 and SAP2 had effectively increased the saturated water content of cinnamon soil. The saturated water content of SAP1 increased from $40.46 \%$ to $54.3 \%$ when the mixing ratio increased from $0.1 \%$ to $1 \%$, and for SAP2, it increased from $39.87 \%$ to $47.69 \%$. It is clear in Figure 2 that the difference in saturated water content between these two kinds of SAPs increased with the increment in the mixing ratio. With a mixing ratio of $0.1 \%$, there was a small difference in the saturated water content of the two composite soils. Both had a saturated water content of around $40 \%$ and a relative increase ratio between $11 \%$ and $13 \%$. When the mixing ratio was over $0.25 \%$, the saturated soil water content of cinnamon composite soil with SAP1 gradually outperformed SAP2. The largest difference occurred with a mixing ratio of $1 \%$, where the saturated soil water content in composite soil with SAP1 was around 14\% more than that in composite soil with SAP2. When compared with the controlled group, the saturated soil content with SAP1 with a mixing ratio of $0.10 \%$ had a relative increment of $13.3 \%$. The most significant increment occurred with a mixing ratio of $1.0 \%$, with a relative increment of $52.10 \%$. The relative increment of saturated soil content with SAP2 also increased between $11.68 \%$ and $33.59 \%$ when compared with the controlled group.

Previous studies on sandy soil indicated than SAP can significantly increase the saturated water content of soil between $11.20 \%$ and $80.00 \%$ compared with the controls [22,25,26]. Moreover, the effect of SAP on saturated soil water content can be varied with types of SAP. Watanabe et al. [25] showed that petroleum-based polymers had better water absorption capacity than starch-based polymers in sandy soil. Bai et al. [28] also showed that among four types of commercial SAPs, sodium polyacrylate and polyacrylamide SAPs were recommended for clay loam soil. The results presented in this section are consistent with the previous research, which showed that the two SAPs used had strong evidence in improving saturated soil content, with relative increment between $11.68 \%$ and $52.10 \%$. Moreover, organic superabsorbent polymer SAP1 was preferable to the cross-linked polyacrylic acid sodium salt polymer SAP2 in cinnamon soil.

\subsection{Characteristics of a Sunken Greenbelt}

\subsubsection{Repeated Water Absorption}

A repeated water absorption test was conducted using a simplified soil column tester. This experiment was conducted to test the water absorption of SAP1, and its reusability was evaluated. The cumulated water absorption of eight replicates is presented in Figure 3. Figure 3a shows the cumulated water absorption of SAP1 composite soil under a 5-year design rainfall intensity. The water absorption was positively correlated with time during the rainfall period, which was the first $60 \mathrm{~min}$. Cumulated water absorption had a sudden downward trend when the input flow stopped at $60 \mathrm{~min}$, and then gradually decreased afterward and finally tended to be stable. The water absorption of composite soil was almost unchanged at $90 \mathrm{~min}$. Similar behavior is shown in Figure $3 \mathrm{~b}$, where the cumulated water absorption of SAP1 composite soil was under a 10-year design rainfall intensity. However, in Figure 3c, there is a sudden change in the cumulated water absorption curve, typically for the 1 st and 7 th water absorption curves. This was because the 15-year design rainfall intensity exceeded the critical rainfall intensity of SAP1 composite soil, which generated surface runoff, and the trend of water absorption slowed down. 

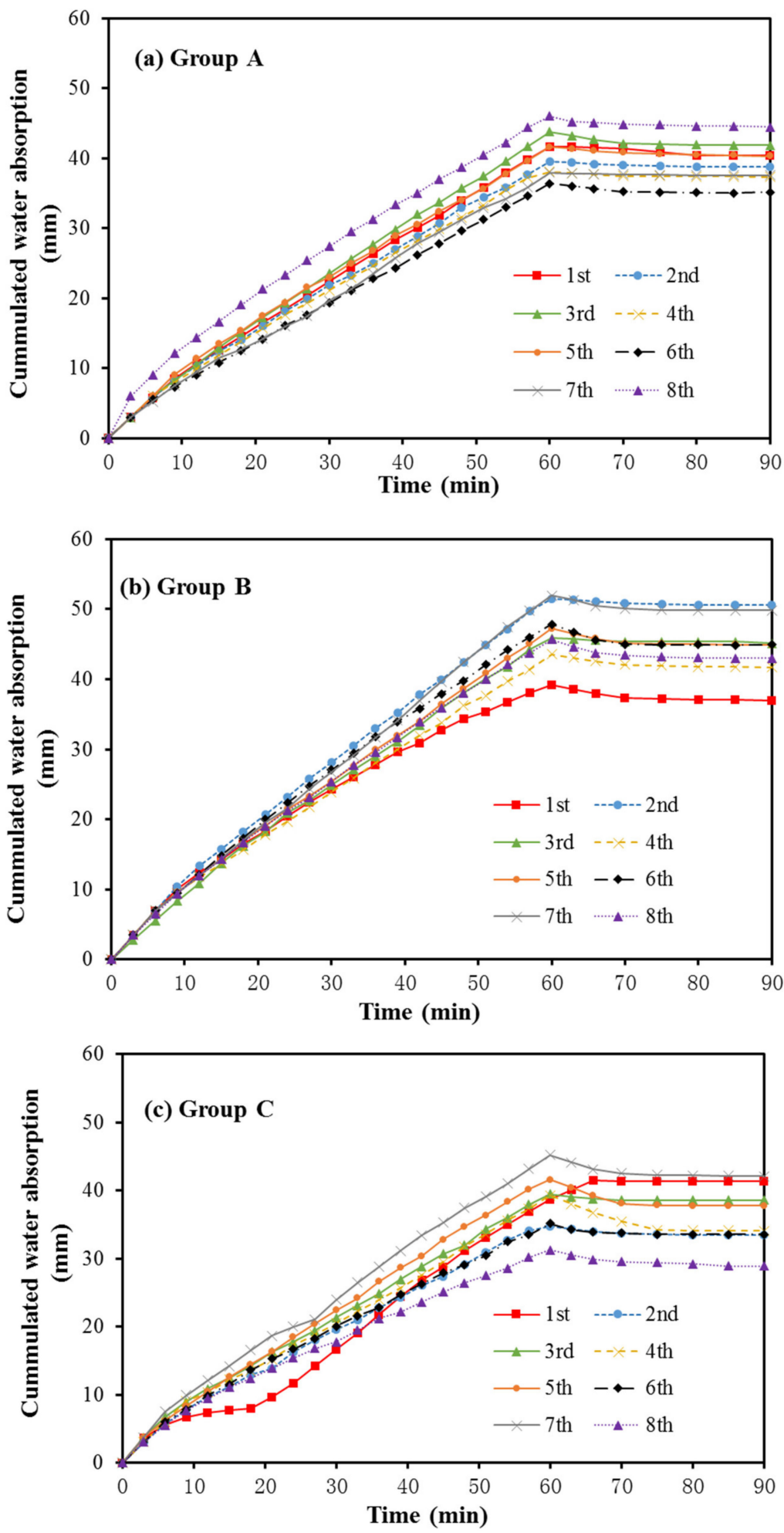

Figure 3. Repeated experiment of cumulated water absorption with (a) Group A with 5-year design rainfall intensity; (b) Group B with 10-year design rainfall intensity; (c) Group C with mixed of 15-year and 5-year design rainfall intensity.

The cumulated water absorption of SAP1 composite soil tended to be stable at $90 \mathrm{~min}$. The stable cumulated water absorption for eight replicates for three groups is presented in Figure 4, which shows that the stable water absorption of SAP1 composite soil was not a monotone decrease between replications, indicating that SAP1 had good reusability. The average cumulated soil water content was 
$39.50 \mathrm{~mm}$ in Group A. The average cumulated soil water content was $44.63 \mathrm{~mm}$ in Group B under 10-year design rainfall intensity. As there was surface runoff generated under 15-year design rainfall intensity, the average cumulated soil water content in Group C was $37.18 \mathrm{~mm}$, which was significantly smaller than that of Group B. Moreover, in the last (8th) replication, the cumulated stable water absorptions were $44.46 \mathrm{~mm}, 43.01 \mathrm{~mm}$, and $36.67 \mathrm{~mm}$ for Group A, Group B, and Group C, respectively, which indicated that SAP1 had very strong water absorption ability and high recycling efficiency.

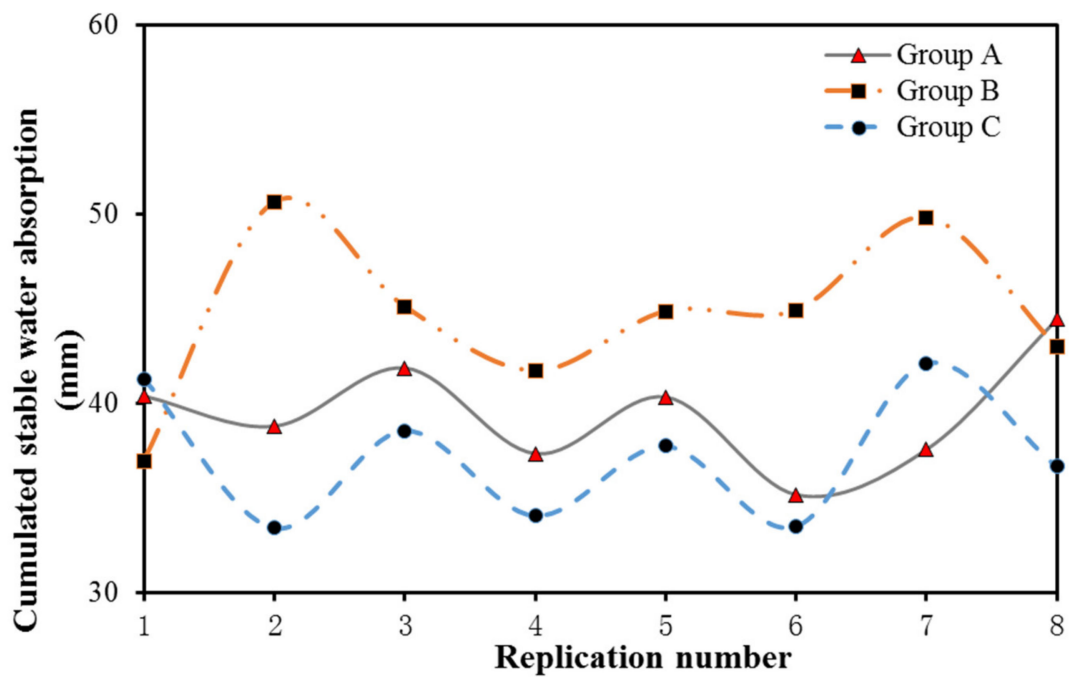

Figure 4. Stable water absorption of composite soils under different design rainfall intensities.

The water absorption of SAP composite soil depended on many factors, such as structures, soil texture, temperature. Bai et al. [28] reported that among temperature, water quality, degree of drying, the repeated water absorption of SAP was highly affected by the degree of drying. When the drying degree was around $90 \%$ for SAPs, the water behavior of SAP decreased around $80 \%$ in the second replication. Similar behavior was reported by Mudiyanselage and Neckers [27]. After the first replication, the swollen SAPs were completely dried in an oven at $100{ }^{\circ} \mathrm{C}$. They reported that water absorption decreased by $80 \%$ in the second replication, and thereafter, no significant reduction was shown between replication 3 and replication 7. As was demonstrated in this study, the SAP1 maintained a high water absorption behavior, which showed different behaviors compared with the previous studies $[27,28]$. The main difference between this study and the previous studies was the SAP composite soil was not dried completely, and the initial soil moisture content was maintained between $11 \%$ and $16 \%$ for each replication, as was shown in Table 1 ; moreover, the SAP composite was dried in an oven at $50^{\circ} \mathrm{C}$, which avoided the potential damage of SAP structure and maintained the high water absorption for SAP1.

\subsubsection{Average Dehydration Time}

The dehydration behavior of the vermiculite-soil layer, SAP composite layer, and activated carbon-quartz sand layer in soil column tester is presented in Figure 5. As is shown in Figure 5, the SAP composite soil layer absorbed infiltrated rainfall quickly during the first hour. Under inflow with 10-year design rainfall intensity, the soil water content of the SAP mixed soil layer increased rapidly from $24.86 \%$ to $40.25 \%$ by $15.39 \%$. Under the 5 -year design rainfall intensity, it increased from $18.61 \%$ to $38.94 \%$, by $20.33 \%$. The soil water content was close to the saturated soil water content $40.46 \%$, as presented in Figure 2. After the first hour, the increase in soil water content in the composite soil layer was relatively slow. The SAP composite soil showed reliable water retention behavior. Even after $300 \mathrm{~h}$ of rainfall, the soil water content in the SAP composite soil layer was still higher, which was $36.54 \%$ and $34.78 \%$, respectively, under 10-year and 5-year design rainfall intensity. Soil water content in the SAP composite soil layer was much higher than those of the vermiculite layer and activated 
carbon-quartz sand layer. It indicated that adding SAP to composite soil had a significant effect on water retention and, therefore, would be beneficial to urban water harvesting.
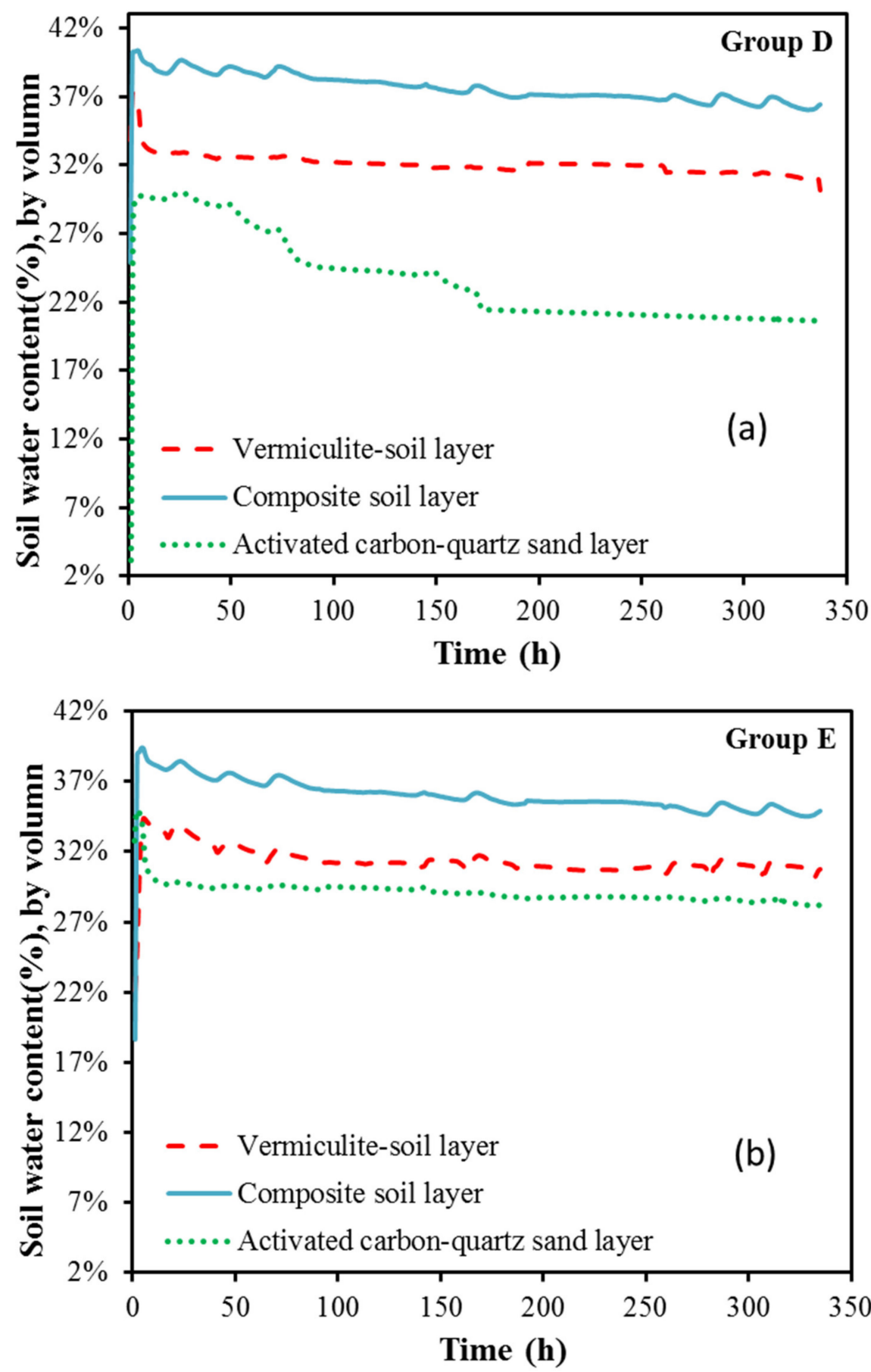

Figure 5. Soil water content for different layers under (a) 10-year design rainfall intensity; (b) 5-year design rainfall intensity.

The activated carbon-quartz sand layer was a filter layer, which had weak water absorption and water retention capacity. As there were many large pores inside the activated carbon-quartz sand layer, the soil water content in this layer could easily infiltrate to the gravel layer. As shown in Figure 5a, under the 10-year design rainfall intensity, the soil water content in quartz sand-activated carbon layer decreased sufficiently within the first $150 \mathrm{~h}$, and tended to be stable, thereafter. Under 5-year designed 
rainfall intensity, the water content of the activated carbon-quartz sand layer increased rapidly in the first hour and also dropped rapidly by $5.34 \%$ in the first $30 \mathrm{~h}$.

The vermiculite-soil layer was laid on the top layer of the composite soil, with a mixing ratio of vermiculite and cinnamon soil of 5:1000. Vermiculite is a soil amendment, which has a small water holding capacity when compared with SAPs. Therefore, the soil water content in the vermiculite-soil layer was highly correlated with cinnamon soil. The soil water content curve of the vermiculite-soil layer was between the composite soil layer and activated carbon-quartz sand layer. Moreover, it can be seen in Figure $5 b$ that the soil water content in the vermiculite-soil layer and SAP layer showed similar trends in soil water content. When the water content in the vermiculite layer was raised by rainfall during the experiment, the soil water content in the SAP composite soil layer also increased. When the soil water content of the vermiculite layer was consumed by evaporation, the soil water content in the SAP composite soil layer also dropped. The average dehydration time of composite soil is also of interest. The results in Figure 5 show that during 14 days, the soil water content in the SAP composite soil was still high, with $36.44 \%$ and $34.90 \%$, respectively, under 10-year and 5-year design rainfall intensity. A fitting curve was fitted through the observed data, and the best-fitting curve $R^{2}>0.9$ is shown in Figure 6. The estimated average dehydration time of composite soil was $1214 \mathrm{~h}$ (50.6 days) and $626 \mathrm{~h}$ (26.1 days) in outdoor conditions under 10-year and 5-year design rainfall intensity, respectively.
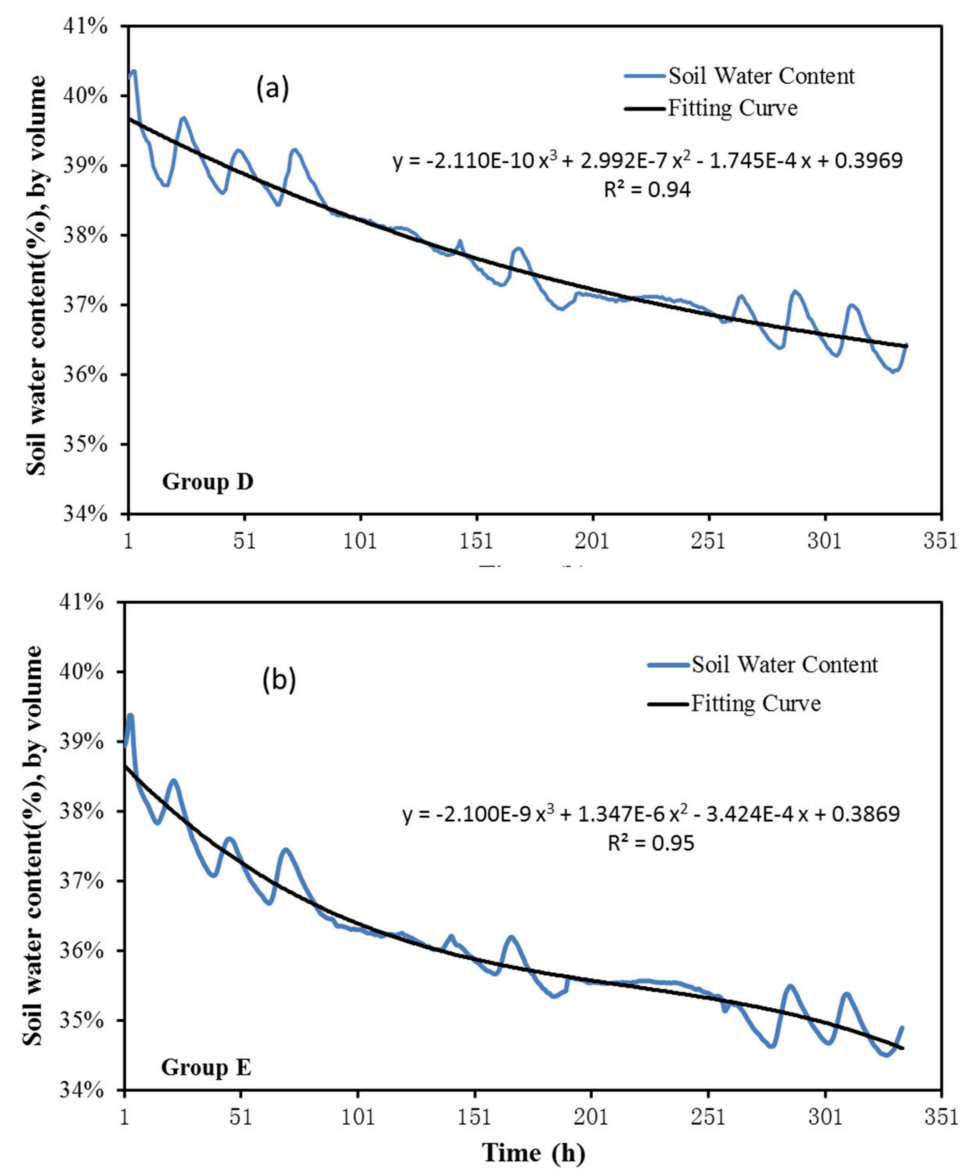

Figure 6. Average dehydration time for composite soil layer of (a) Group D on 16 December 2016; (b) Group E on 16 December 2016.

SAP can effectively improve the average dehydration time. Khodadadi Dehkordi [26] reported sandy soil without SAP dried up within 4 days, and SAPs increased the average dehydration time by 6 to 9 days. Watanabe et al. [25] showed that the soil water content gradually decreased to zero at 15 days after planting in the control group, as well as mostly in the starch-based polymer composite 
soil, while petroleum-based polymer still held high soil water content. The results in this experiment showed consistent results as with these previous researches. It showed that SAP1 composite soil had an even longer average dehydration time, which was 50.6 days and 26.1 days, under 10-year and 5 -year design rainfall intensity, respectively. This was mainly because of low evaporation and potential soil moisture recharger by dew and rainfall. SAP composite soil was assembled in the second layer in the soil column tester, and the experiment was conducted in winter, which inhibited soil moisture evaporation. Moreover, as the experiment was conducted in outdoor conditions, the potential soil moisture recharger by dew and rainfall, which was not taken into consideration, could also have extended the dehydration time for SAP1 composite soil.

\section{Conclusions}

This paper investigated the saturated water content of cinnamon soil mixed with two SAPs with mixing ratios of $0.1 \%, 0.25 \%, 0.5 \%, 0.75 \%$, and $1 \%$. The repeated water absorption behavior of SAP composite soil and its average dehydration time were investigated through a soil column tester under different design rainfall intensities. The following conclusions were obtained:

(I) SAPs showed a significant effect on improving the saturated soil water content for cinnamon, and the relative increment varied from $11.68 \%$ to $52.10 \%$. The organic superabsorbent polymer SAP1 was preferable to the cross-linked polyacrylic acid sodium salt polymer SAP2 in cinnamon soil.

(II) SAP1 showed high recycling efficiency in the soil column test. The composite soil maintained a high cumulated water absorption in the 8th replication, with $44.46 \mathrm{~mm}, 43.01 \mathrm{~mm}$, and 36.67 mm for Group A, Group B, and Group C, respectively.

(III) The SAP composite soil layer had higher water retention behavior. The average dehydration time for SAP composite soil under 5-year and 10-year design rainfall intensities was $626 \mathrm{~h}$ and 1214 h, respectively.

Author Contributions: Conceptualization, Y.Q. and T.Y.; methodology, Y.Q.; software, P.S.; validation, Y.Q., P.S. and Z.L.; formal analysis, Y.Q.; investigation, Y.Q.; resources, T.Y.; data curation, S.W. and F.H.; writing-original draft preparation, S.W.; writing-review and editing, Y.Q.; visualization, Y.Q.; supervision, T.Y.; project administration, T.Y.; funding acquisition, T.Y. All authors have read and agree to the published version of the manuscript.

Funding: This study was partially supported by the National Natural Science Foundation of China (51909060: 51879068), the China Postdoctoral Science Foundation (2018M642153).

Conflicts of Interest: The authors declare no conflict of interest.

\section{References}

1. Prince George's County, Department of Environmental Resource Programs. Low-Impact Development: An Integrated Design Approach; Programs and Planning Division: Largo, MD, USA, 1999.

2. Dietz, M.E. Low Impact Development Practices: A Review of Current Research and Recommendations for Future Directions. Water Air Soil Pollut. 2007, 186, 351-363. [CrossRef]

3. Eckart, K.; McPhee, Z.; Bolisetti, T. Performance and implementation of low impact development-A review. Sci. Total Environ. 2017, 607-608, 413-432. [CrossRef]

4. Jayasooriya, V.M.; Ng, A.W.M. Tools for Modeling of Stormwater Management and Economics of Green Infrastructure Practices: A Review. Water Air Soil Pollut. 2014, 225, 2055. [CrossRef]

5. Liu, L.; Jensen, M.B. Green infrastructure for sustainable urban water management: Practices of five forerunner cities. Cities 2018, 74, 126-133. [CrossRef]

6. Li, H.; Ding, L.; Ren, M.; Li, C.; Wang, H. Sponge City Construction in China: A Survey of the Challenges and Opportunities. Water 2017, 9, 594. [CrossRef]

7. Jia, H.; Wang, Z.; Zhen, X.; Clar, M.; Yu, S.L. China's sponge city construction: A discussion on technical approaches. Front. Environ. Sci. Eng. 2017, 11, 18. [CrossRef]

8. Mei, C.; Liu, J.; Wang, H.; Yang, Z.; Ding, X.; Shao, W. Integrated assessments of green infrastructure for flood mitigation to support robust decision-making for sponge city construction in an urbanized watershed. Sci. Total Environ. 2018, 639, 1394-1407. [CrossRef] 
9. Li, Q.; Wang, F.; Yu, Y.; Huang, Z.; Li, M.; Guan, Y. Comprehensive performance evaluation of LID practices for the sponge city construction: A case study in Guangxi, China. J. Environ. Manag. 2019, 231, 10-20. [CrossRef]

10. Zhang, S.; Li, Y.; Ma, M.; Song, T.; Song, R. Storm Water Management and Flood Control in Sponge City Construction of Beijing. Water 2018, 10, 1040. [CrossRef]

11. Zhou, J.; Liu, J.; Shao, W.; Yu, Y.; Zhang, K.; Wang, Y.; Mei, C. Effective Evaluation of Infiltration and Storage Measures in Sponge City Construction: A Case Study of Fenghuang City. Water 2018, 10, 937. [CrossRef]

12. Chan, F.K.S.; Griffiths, J.A.; Higgitt, D.; Xu, S.; Zhu, F.; Tang, Y.-T.; Xu, Y.; Thorne, C.R. "Sponge City" in China-A breakthrough of planning and flood risk management in the urban context. Land Use Policy 2018, 76, 772-778. [CrossRef]

13. Dong, R.; Zhang, X.; Li, H. Constructing the Ecological Security Pattern for Sponge City: A Case Study in Zhengzhou, China. Water 2019, 11, 284. [CrossRef]

14. Zohourian, M.M.; Kabiri, K. Superabsorbent polymer materials: A review. Iran. Polym. J. 2008, 17, 451-477.

15. Behera, S.; Mahanwar, P.A. Superabsorbent polymers in agriculture and other applications: A review. Polym. Plast. Technol. Mater. 2020, 59, 341-356. [CrossRef]

16. Fernando, T.N.; Ariadurai, S.A.; Disanayaka, C.K.; Kulathunge, S.; Aruggoda, A.G.B. Development of Radiation Grafted Super Absorbent Polymers for Agricultural Applications. Energy Procedia 2017, 127, 163-177. [CrossRef]

17. Demitri, C.; Scalera, F.; Madaghiele, M.; Sannino, A.; Maffezzoli, A. Potential of Cellulose-Based Superabsorbent Hydrogels as Water Reservoir in Agriculture. Int. J. Polym. Sci. 2013, 2013, 435073. [CrossRef]

18. Bai, W.; Zhang, H.; Liu, B.; Wu, Y.; Song, J. Effects of super-absorbent polymers on the physical and chemical properties of soil following different wetting and drying cycles. Soil Use Manag. 2010, 26, 253-260. [CrossRef]

19. Chen, P.; Zhang, W.A.; Luo, W.; Fang, Y.e. Synthesis of superabsorbent polymers by irradiation and their applications in agriculture. J. Appl. Polym. Sci. 2004, 93, 1748-1755. [CrossRef]

20. Raju, K.M.; Raju, M.P.; Mohan, Y.M. Synthesis of superabsorbent copolymers as water manageable materials. Polym. Int. 2003, 52, 768-772. [CrossRef]

21. Snoeck, D.; Van den Heede, P.; Van Mullem, T.; De Belie, N. Water penetration through cracks in self-healing cementitious materials with superabsorbent polymers studied by neutron radiography. Cem. Concr. Res. 2018, 113, 86-98. [CrossRef]

22. Yang, L.; Yang, Y.; Chen, Z.; Guo, C.; Li, S. Influence of super absorbent polymer on soil water retention, seed germination and plant survivals for rocky slopes eco-engineering. Ecol. Eng. 2014, 62, 27-32. [CrossRef]

23. Suresh, R.; Prasher, S.O.; Patel, R.M.; Qi, Z.; Elsayed, E.; Schwinghamer, T.; Ehsan, A.M. Super Absorbent Polymer and Irrigation Regime Effects on Growth and Water Use Efficiency of Container-Grown Cherry Tomatoes. Trans. ASABE 2018, 61, 523-531. [CrossRef]

24. Li, L.; Chen, M.; Zhou, X.; Lu, L.; Li, Y.; Gong, C.; Cheng, X. A case of water absorption and water/fertilizer retention performance of super absorbent polymer modified sulphoaluminate cementitious materials. Constr. Build. Mater. 2017, 150, 538-546. [CrossRef]

25. Watanabe, K.; Saensupo, S.; Na-iam, Y.; Klomsa-ard, P.; Sriroth, K. Effects of Superabsorbent Polymer on Soil Water Content and Sugarcane Germination and Early Growth in Sandy Soil Conditions. Sugar Tech 2019, 21, 444-450. [CrossRef]

26. Khodadadi Dehkordi, D. Effect of superabsorbent polymer on soil and plants on steep surfaces. Water Environ. J. 2018, 32, 158-163. [CrossRef]

27. Mudiyanselage, T.K.; Neckers, D.C. Highly absorbing superabsorbent polymer. J. Polym. Sci. Part A Polym. Chem. 2008, 46, 1357-1364. [CrossRef]

28. Bai, W.; Song, J.; Zhang, H. Repeated water absorbency of super-absorbent polymers in agricultural field applications: A simulation study. Acta Agric. Scand. Sect. B Soil Plant Sci. 2013, 63, 433-441. [CrossRef]

(C) 2020 by the authors. Licensee MDPI, Basel, Switzerland. This article is an open access article distributed under the terms and conditions of the Creative Commons Attribution (CC BY) license (http://creativecommons.org/licenses/by/4.0/). 